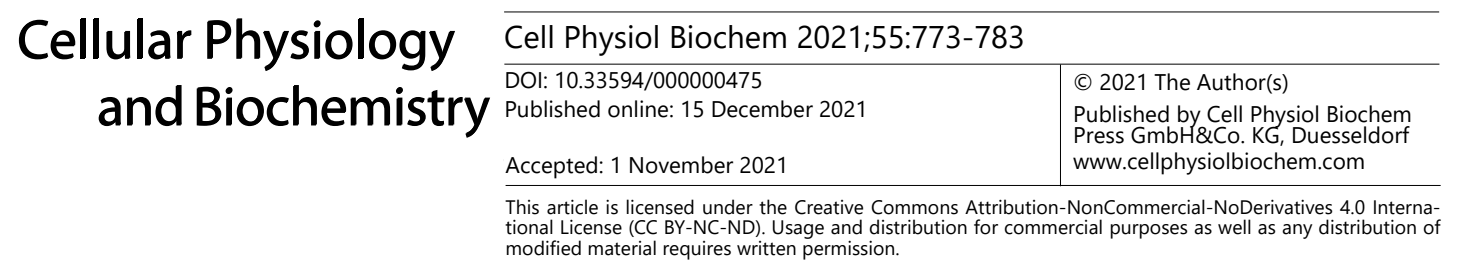

\title{
Apolipoprotein E4 as a Novel Treatment Target for Alzheimer's Disease
}

\author{
Jamieson Lachlan Jervies Samuel Peter King Cenk Suphioglu \\ NeuroAllergy Research Laboratory (NARL), School of Life and Environmental Sciences (LES), Faculty of \\ Science, Engineering and Built Environment (SEBE), Deakin University, Waurn Ponds, Victoria, Australia
}

\author{
Key Words \\ ApoE4 • Alzheimer's Disease • Amyloid Beta • Tau Phosphorylation • COVID-19
}

\begin{abstract}
The importance of Alzheimer's Disease (AD) research has never been greater from a worldwide perspective with the disease becoming increasingly prevalent with life expectancy on the rise. One emerging factor that has presented as a serious risk that still requires more research and understanding is the role and effects of Apolipoprotein E4 (ApoE4). When present, individuals are three times more likely to develop AD in their lifetime. This is due to ApoE4's ability to not only increase amyloid beta plaque aggregation ApoE4 also increases hyperphosphorylation of tau causing neurofibrillary tangles. These two factors are the well-known hallmarks for $A D$, which increase the importance for ApoE4 research as it affects both major aspects. Treatment for $A D$ has always been an issue due to a variety of factors with only a few approved for use today. These approved treatments are only to ease and supress symptoms rather than treating the disease. Dementia symptoms such as memory loss, language problems, motor skills, irritability and paranoia are all symptoms that destroy patient's ability to function in their communities. Inhibiting ApoE4 and reducing its toxic effects is a promising theory that has the ability to extend $A D$ patients' lifespan and prolong capable brain function limiting brain tissue degradation.

(C) 2021 The Author(s). Published by Cell Physiol Biochem Press GmbH\&Co. KG
\end{abstract}

\section{Neurodegenerative Diseases}

Neurodegenerative diseases present in a variety of conditions, however, are caused by the damage, death and loss of neurons. The degradation of these neuronal cells causes many debilitating and often incurable diseases which leads to a large burden not only on the affected individual but their support network and society both personally and financially. The impact of disease forms a progressive decline in cognitive and motor function which at later stages of progression requires extensive care and assistance [1]. 


\section{Cellular Physiology Cell Physiol Biochem 2021;55:773-783 \begin{tabular}{ll|l} 
and Biochemistry & $\begin{array}{l}\text { DOI: 10.33594/000000475 } \\
\text { Published online: 15 December 2021 }\end{array}$ & $\begin{array}{l}\text { C } 2021 \text { The Author(s). Published by } \\
\text { Cell Physiol Biochem Press GmbH\&Co. KG }\end{array}$
\end{tabular} \\ Jervies et al.: Apolipoprotein E4 in Alzheimer's Disease}

Neurodegenerative diseases are becoming more prevalent worldwide due to current increases in life expectancy and therefore ageing population. The increase in the ageing population is causing disease rates to increase as age is the primary risk factor for most neurodegenerative diseases with one out of every ten individuals aged over 65 years impacted by Alzheimer's disease alone [2].

\section{Alzheimer's Disease}

Alzheimer's disease (AD) is the most common cause of dementia accounting for up to $80 \%$ of all dementia diagnoses [3]. In Australia dementia and AD account for $11 \%$ of deaths which makes it the second leading cause of death only behind coronary heart disease making up 13\%. Dementia and AD are also the leading cause of death for females in Australia [4].

AD diagnosis and categorisation are still not perfect with each case falling into three broad categories. As shown in Table 1 these are early-onset Alzheimer's, late-onset Alzheimer's disease and Familial Alzheimer's disease (FAD). FAD is a form of AD that medical professionals can pinpoint a link in genetic inheritance. At this stage of current knowledge and testing, this only makes up less than one percent of all cases of AD. Early-onset Alzheimer's occurs in individuals younger than 65 years of age and is seen in approximately five percent of cases. People with previous conditions such as Down Syndrome are at higher risk of developing this form of AD [5]. Finally, late-onset Alzheimer's is the most common form of the disease with age being the greatest risk factor.

\section{Symptoms}

Alzheimer's disease is the most common cause of dementia which is the progressive decline of at least two cognitive domains. These include language, memory, behaviour and personality which impact the everyday life of those afflicted. Dementia was discovered and recorded back in 1907 by Aloysius Alzheimer after accurately describing a 51-year-old woman's symptoms however the concept of the disease has existed for thousands of years before [6].

Early defined features of AD included amyloid beta plaques and intracellular neurofibrillary tangles of tau. However, during research, the features are known to include degradation in the cerebral cortex and subcortical regions of the brain by neuronal and synaptic apoptosis [7]. Apoptosis continues to degrade brain tissue with the greatest cluster volumes of atrophy in the posterior hippocampus, thalamus and middle cingulate gyrus [8].

The gradual continuation of brain atrophy (Fig. 1) causes serious symptoms that possibly become dangerous to the inflicted and surrounding people as loss of motor skills and increased levels of paranoia, hallucinations, memory loss, language problems, irritability and anxiety [10]. Levels of tissue degradation increase over time with increasingly severe symptoms that eventually cause debilitating function until death.

Table 1. Representing the key differences between the 3 types of Alzheimer's Disease. Showing the difference in those affected, occurrence rates and main genetic risk factors from each category

\begin{tabular}{|c|c|c|}
\hline Early-onset Alzheimer's Disease & Late-onset Alzheimer's Disease & Familial Alzheimer's Disease \\
\hline Effects patients less than 65 years of age. & Effects patients greater than 65 years of age. & Usually impacted prior to 65 years of age. \\
\hline $5 \%$ of all Alzheimer's Disease cases. & $\begin{array}{l}\text { Most common form approximately } 95 \% \text { of } \\
\text { cases. }\end{array}$ & $\begin{array}{l}\text { Less than } 1 \% \text { of all Alzheimer's Disease } \\
\text { cases. }\end{array}$ \\
\hline \multirow[t]{2}{*}{$\begin{array}{l}\text { Caused by variants in the Amyloid Precursor } \\
\text { Protein (APP), Presenilin } 1 \text { (PSEN1) and } \\
\text { Presenilin } 2 \text { (PSEN2) genes. }\end{array}$} & $\begin{array}{l}\text { Linked with number of genetic variants most } \\
\text { well-known occurrent in Apolipoprotein } \\
\text { (APOE) gene. }\end{array}$ & $\begin{array}{l}\text { Inherited, genetic abnormality passed } \\
\text { down. }\end{array}$ \\
\hline & & $\begin{array}{l}\text { Falls under Early-onset Alzheimer's } \\
\text { Disease category. }\end{array}$ \\
\hline
\end{tabular}




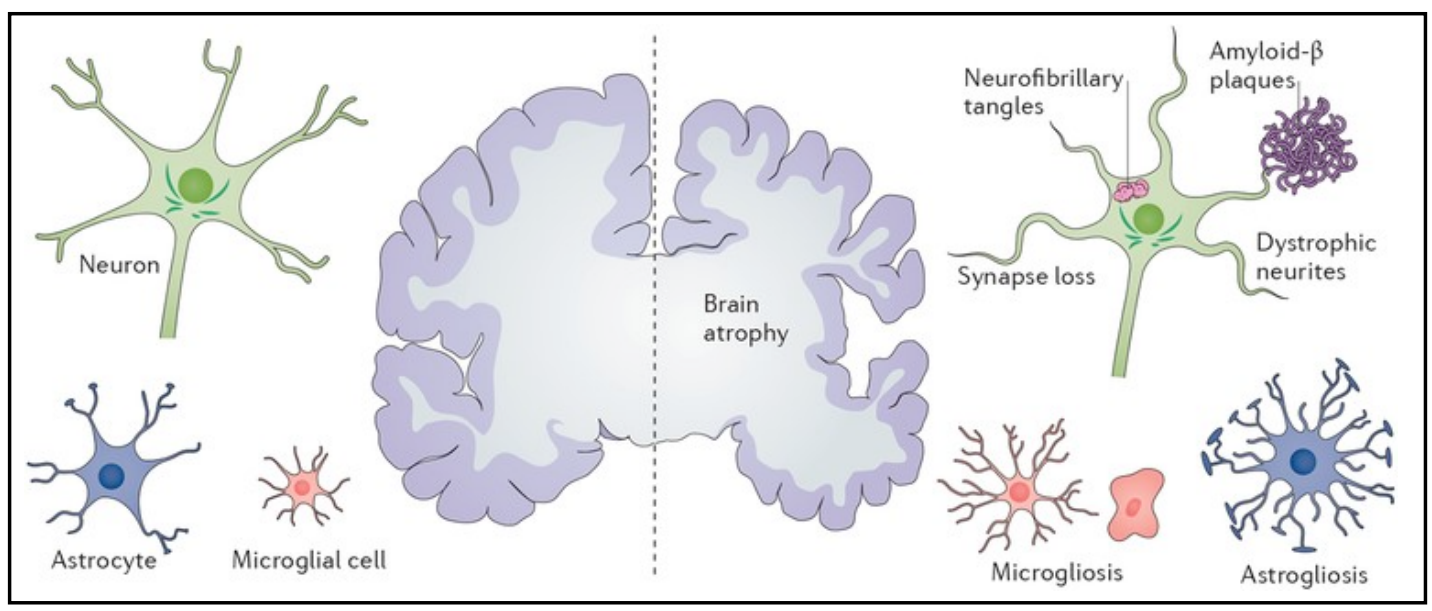

Fig. 1. Effect of Alzheimer's disease hallmarks on the brain. Human brain - comparison between healthy and Alzheimer's disease sufferer. Brain atrophy demonstrated by neuron damage and synaptic loss. This is caused from the hallmarks of Alzheimer's disease, deposits of amyloid beta plaques and neurofibrillary tangles of tau. Diagram Sourced from Congdon, et al. [9].

The major intervention targets being considered today still include amyloid beta plaques and hyperphosphorylated tau protein tangles, however oxidative stress and neuroinflammation have also been identified in the disease pathogenesis. Disease progression is continued by these factors as pathological pathways become linked together and collaboratively drive the development of AD [11]. Therefore, it has been established that targeting only one pathway or target of disease progression is looking less likely to yield beneficial results.

\section{Amyloid Beta Formation}

Amyloid beta peptide $(A \beta)$ is formed from the transmembrane protein, amyloid precursor protein (APP) via $\beta$ - and $\gamma$-secretase processing [12]. A $\beta$ aggregates on the walls of cerebral arteries due to the high rate of flow into the plasma and cerebrospinal fluid developing stages of cerebral vascular disease (CVD). CVD is known for the promotion of $A \beta$ production and deposit leading to the increasing development of AD [13].

B-amyloids that begin to build up are folded into the $\beta$-pleated shape and stack upon each other forming aggregates and long fibrils which are known as plaques [14]. A $\beta$ plaques are generally composed of $A \beta 42$ named for the 42 amino acid residues that make it up. This has been found to be toxic to surrounding neuronal cells adding to the progression of many neurodegenerative diseases especially AD [15].

$\mathrm{A} \beta$ reduction has been a major research target for $\mathrm{AD}$ prevention and treatment for a long period of time due to its significant impact on the brain in affected individuals (Fig. 1). Research thus far has not provided the hoped-for benefits, especially in human clinical trials. While it has not shown the results that once were theorised, many possibilities remain undiscovered in terms of potential.

\section{Tau Phosphorylation}

Tau is a protein most commonly found in neurons and has an important role in the assembly and stabilisation of the internal microtubules. This is completed by binding these microtubules through microtubule-binding domains. The human tau protein is coded from 
the MAPT gene located upon chromosome 17, translated from a 6-kb mRNA transcript for the central nervous system (CNS) and a 9-kb transcript for the peripheral nervous system [16].

Tau was originally thought to be mainly present within neuronal axons which is true, however, over time it has become apparent that tau also accumulates in dendrites [17]. The accumulation occurs in dendritic spines contributing to excitotoxicity alongside the axonal build up. There are six isoforms of tau produced from splicing at the MAPT gene with each isoform containing 3 (3R) or 4 (4R) repeat domains [18].

Tau protein is involved in various physiological processes via the binding with selective molecules such as signalling molecules, lipids and cytoskeletal elements to regulate axonal diameter and growth, vesicle and organelle transport as well as controlling signalling cascades by forming a protein scaffold [19].

Hyperphosphorylated tau causes neurofibrillary deposits that are prevalent in several neurodegenerative diseases including but not limited to AD, Progressive Supranuclear Palsy (PSP), Chronic Traumatic Encephalopathy (CTE) and Traumatic Brain Injury (TBI) [20]. It has become apparent throughout research that the alterations to form abnormal tau cause it to become soluble and induces neurodegeneration (Fig. 1) [21].

Tau dissociates from the microtubules it was previously bonded to during hyperphosphorylation as it substitutes the configuration of two phosphates per protein molecule [22]. Once hyperphosphorylation occurs tau monomers aggregate firstly into oligomers in route of neurofibrillary tangles (NFT) increasing neurotoxicity leading to Alzheimer's disease and other neurodegenerative diseases labelled as tauopathies [23].

\section{ApoE4 Presence and Production}

The APOE gene encodes instructions for the transcription and translation of a group of proteins called apolipoprotein E (ApoE). The sequence is located on chromosome 19 alongside apolipoprotein C1 and C2 genes. Once formed the ApoE protein consists of 299 amino acids in humans [24]. ApoE is expressed in multiple organs throughout the body with the highest levels of expression found in the liver and brain. Astrocytes have been found alongside other non-neuronal cells to be the highest contributors to ApoE expression within the brain [25].

There are known to be at least three different alleles of the APOE gene these are the e2, e3 and e4 versions (ApoE2, ApoE3 and ApoE4). ApoE3 is the most common variant of the gene being present in approximately $75 \%$ of the human population [26]. The APOE gene variants play a large role within $\mathrm{AD}$ as $\mathrm{ApoE} 4$ is one of the most important genetic risk factors of the disease behind ageing. ApoE3 being the most common form of ApoE has been found to be neutral in the progression of $\mathrm{AD}$ with $\mathrm{ApoE} 2$ showing protective qualities against the disease [27].

The presence of ApoE4 has increased the chances of developing AD by three times as much in carriers of the gene. However, even though the potential for ApoE4 as a therapeutic target seems extremely promising in the 27 years since the possibility was identified, a very limited number of drugs have been approved [28].

Research evidence has been found to suggest that the presence of ApoE4 impedes and interrupts $A \beta$ clearance and causes microglial dysregulation [29]. Microglial dysregulation causes extreme issues within the brain as they are key in maintaining homeostasis, brain development and physiology throughout the ageing process [30].

$\mathrm{A} \beta$ clearance has thought to be affected in many situations by the presence of ApoE4. It has been identified that astrocytes and microglia produce an $A \beta$ degrading protease called neprilysin [31]. ApoE4 actively impedes the function of both astrocytes and microglia reducing the $A \beta$ clearance and forming a build-up leading to $A \beta$ plaques that are known to progress AD. However, it has been found that ApoE4 could also have impacts on other factors 


\section{Cellular Physiology Cell Physiol Biochem 2021;55:773-783 \\ \begin{tabular}{ll|l} 
and Biochemistry $10.33594 / 000000475$ & Published online: 15 December 2021 & 2021 The Author(s). Published by \\
Cell Physiol Biochem Press GmbH\&Co. KG
\end{tabular} \\ Jervies et al.: Apolipoprotein E4 in Alzheimer's Disease}

including lipid metabolism, tau pathology, neural development, synaptic plasticity, neuro vascularisation and inflammation all of which could be important factors in $A D$ pathogenesis [32].

The presence of ApoE4 increases tau neurotoxicity leading to the early onset of AD. The first detectable pathology in the human brain that resembles AD is the Pretangle Tau located in the noradrenergic locus coeruleus (LC) [33]. The noradrenergic LC is the main source for norepinephrine which supplies areas within the cortical and subcortical regions of the brain which are affected in AD [34]. Recent research has indicated the presence of ApoE4 inhibits noradrenaline transport of which can allow an increase in the aggregation of the tau protein [35]. However, the exact relationship and cause between ApoE4 and Tau in the LC has yet to be determined and will be an interest for future research.

\section{ApoE4 Relation with COVID-19}

ApoE4 has also become a point of research worldwide with its relationship with SARS$\mathrm{CoV}-2$, the APOE gene is a more impactful avenue of research than ever before. ApoE4 has recently been linked with increased infection and severity of COVID-19. The ApoE4 genotype variant showed a strong risk for severe hospitalised COVID-19 patients compared to ApoE2/3, independent of pre-existing comorbidities [36].

Cells expressing ApoE4 were found to be more vulnerable to SARS-CoV-2 infection via an in vitro study. Using human-induced pluripotent stem cells (hiPSC), cells expressing ApoE4 proved to increase SARS-CoV-2 infection significantly. This alongside results that proved a rise in toxic pathogenic effects in ApoE4 astrocytes compared to that of ApoE3 astrocytes indicates a high-risk factor in the COVID-19 battle for individuals with the ApoE4 genotype [37].

However, this research has been limited and only so far identified that a relationship for higher infection and severity of SARS-CoV-2 for ApoE4 carriers does exist. The pathway and interactions between molecules that cause this genetic vulnerability are still greatly unknown. This sets up the possibility for future research to combat the severity of COVID-19 pathology in ApoE4 carrier patients [38]. Further research will not only assist the prevention of severe COVID-19 infection but increasing knowledge into how ApoE4 affects various cells could lead to alternative approaches within other research such as Alzheimer's Disease.

\section{Diagnosis}

Diagnosis of $\mathrm{AD}$ has proved difficult over the years with no sure way to determine the presence of the disease without a post-mortem autopsy. In 1901 Alois Alzheimer was the first to accurately describe and detail a case of a 51-year-old woman by the name of Auguste D. with a reported untreatable paranoid symptomatology. Her husband noticed symptoms of paranoia, progressive sleep and memory disturbance, aggression and confusion [39]. This continued to her death on April 8, 1906, an autopsy was completed on the brain which was investigated histologically. The autopsy resulted in a discovery of changes in the neurofibrils. An accumulation of thick tangled fibrils in normal neurons was observed to the point in which the nucleus and cytoplasm disappeared, and the healthy appearing neuron was lost [40].

Diagnosis from this original point of AD knowledge became analysing patients concerning generalised symptoms of memory loss, irritability, and disorientation. Individuals were classed strictly to those who clearly suffered from these symptoms and were classified as 'demented' and those who were not. This method was impractical as it didn't allow for progressive degeneration due to the slow accumulation of $A \beta$ deposits and hyperphosphorylated tau [41]. 
Table 2. Pros and cons of various methods of diagnosis. Generally, these methods are used in conjunction to determine Alzheimer's Disease diagnosis as one test alone is inconclusive

\begin{tabular}{|c|c|c|}
\hline Type of Diagnosis & Pros & Cons \\
\hline $\begin{array}{l}\text { Brain Imaging (MRI, CT } \\
\text { and PET) }\end{array}$ & $\begin{array}{l}\text { - Visually provides results of brain structure, } \\
\text { level of brain atrophy. } \\
\text { - Rules out other diseases that symptoms } \\
\text { could be reflecting. }\end{array}$ & $\begin{array}{l}\text { - Conducted over time, usually over several years to } \\
\text { measure decline. } \\
\text { - Diagnosis via exclusion which is very time consuming to } \\
\text { result in a diagnosis. } \\
\text { - Only provides evidence of brain atrophy in certain } \\
\text { regions, symptoms may be predicted but other tests are } \\
\text { required. }\end{array}$ \\
\hline $\begin{array}{l}\text { Physical/Neurological } \\
\text { Exam }\end{array}$ & $\begin{array}{l}\text { Measures decline in motor/language skills, } \\
\text { showing level of symptom progression. } \\
\text { - Non-invasive can be conducted anywhere. }\end{array}$ & $\begin{array}{l}\text { - Conducted over time, usually over several years to } \\
\text { measure decline. } \\
\text { - Results can be interpreted slightly different depending } \\
\text { on who is running the exam. } \\
\text { - Results can be affected by other factors including other } \\
\text { diseases or illnesses and old age. }\end{array}$ \\
\hline Genetic Marker Test & $\begin{array}{l}\text { - Provides very early insight into genetic risk } \\
\text { factors present in pateints. } \\
\text { - Quick can be conducted at one time. }\end{array}$ & $\begin{array}{l}\text { - Only provides results about increased risk. } \\
\text { - Inconclusive, results in many false positives. }\end{array}$ \\
\hline
\end{tabular}

Many strategies have been conducted to improve the ability to detect AD in living humans, with some positive results. An option for early detection that has been researched and is continuingly being improved is the use of biomarkers especially blood-based molecular biomarkers. Biomarkers can be any type of naturally occurring molecule for the testing of $A D$. Plasma levels of $A \beta$ and tau are being researched heavily as they show promise in determining which candidates have progressive $\mathrm{AD}$ by the quantity of these biomarkers in their blood [42].

Brain scans have been utilised for many years with the use of computed tomography (CT), magnetic resonance imaging (MRI) and positron emission tomography (PET) technologies. These scans have been used to rule out possible causes for AD making the diagnosis one from exclusion (Table 2). Due to the lack of specific findings radiologists often cannot make a specific diagnosis of the presence of AD [43]. However, recently PET scans have been emerging in a way to diagnose and manage AD with the use of amyloid imaging. Various radiotracers have been utilised in experiments to allow in vitro detection of $A \beta$ deposits in the brain with the use of PET scans [44].

Another method of $\mathrm{AD}$ diagnosis is using genetic markers, these markers are used to identify early onset AD. One of the major genetic markers used is the amyloid precursor protein (APP). The correlating gene for APP is located on chromosome 21 and increases the level of $A \beta$ production. This was originally identified in Down syndrome patients when they live over 30 years of age pathological and clinical factors became present [45]. This is due to the fact of having an extra copy of chromosome 21 led to a higher production of APP and therefore leading to higher deposits of $A \beta$. Presenilin 1 (PSEN1) and presenilin 2 (PSEN2) are two other genetic factors that cause autosomal dominant early onset AD through mutations and duplications [46]. PSEN1 and PSEN2 genes code for a component integral to y-secretase responsible for the formation of $A \beta$ peptides through sequential proteolytic cleavage of APP [47].

\section{Treatments}

Although AD provides significant public health risk, treatment for the disease is extremely limited. Only a handful of established treatments are approved for use today which all are used to control symptoms rather than slow or alter the progression of the disease [48]. Currently, the treatments available are to ease symptoms of agitation, aggression, nonconvulsive seizures, and cognitive impairment.

Three of the approved are cholinesterase inhibitors designed to block the enzyme acetylcholinesterase which is increased in production during ageing. Acetylcholinesterase 
has been known to degrade the neurotransmitters of the brain. Therefore, the use of cholinesterase inhibitors ideally improves cholinergic function [49]. Acetylcholine plays an important role in brain function due to its ability to control and alter neuronal excitability, firing groups of neurons, synaptic plasticity and synaptic transmission [50]. Rivastigmine, donepezil and galantamine are currently the only three cholinesterase inhibitors approved for usage in Australia, the United States of America and the European Union as well as many other regions. These three therapeutics have only been beneficial in the early stages of AD, as early stages provide the possibility of retaining acetylcholine [51].

Another approved treatment option is a N-methyl-D-aspartate (NMDA) receptor antagonist known as memantine. NMDA receptor is an ion channel protein and glutamate receptor found in nerve cells. It plays a key role in the synaptic transmission and synaptic plasticity in regions of the brain dedicated to learning and memory [52]. The NMDA receptor is activated by glutamate to open an ion channel non-selective of cations to transfer through. Magnesium ion forms a blockade by binding at specific sites of the NMDA receptor to stop the flow of sodium, potassium and calcium ions. However, prolonged and strong glutamate release from presynaptic terminals causes depolarisation and therefore removes the magnesium ion to allow the large flow of calcium ions [53]. An influx of calcium ions has been shown to have critical effects on synaptic plasticity, common pathological effects of AD.

Rivastigmine, donepezil, galantamine and memantine are currently used in reducing the progression of $\mathrm{AD}$ symptoms. Therefore, they are useful in the early stages but get less effective as the disease progresses. This leaves the issue relating to the treatment of the main causes of $\mathrm{AD}$, which are $\mathrm{A} \beta$ aggregation and neurofibrillary tangles. Ongoing research efforts are constant for the primary and secondary prevention of $A D$, with direction towards therapeutic targets. This consists of both $\mathrm{A} \beta$ aggregation and tau phosphorylation processes, as well as neurochemicals, mitochondria, inflammatory pathways and neuroglia [54].

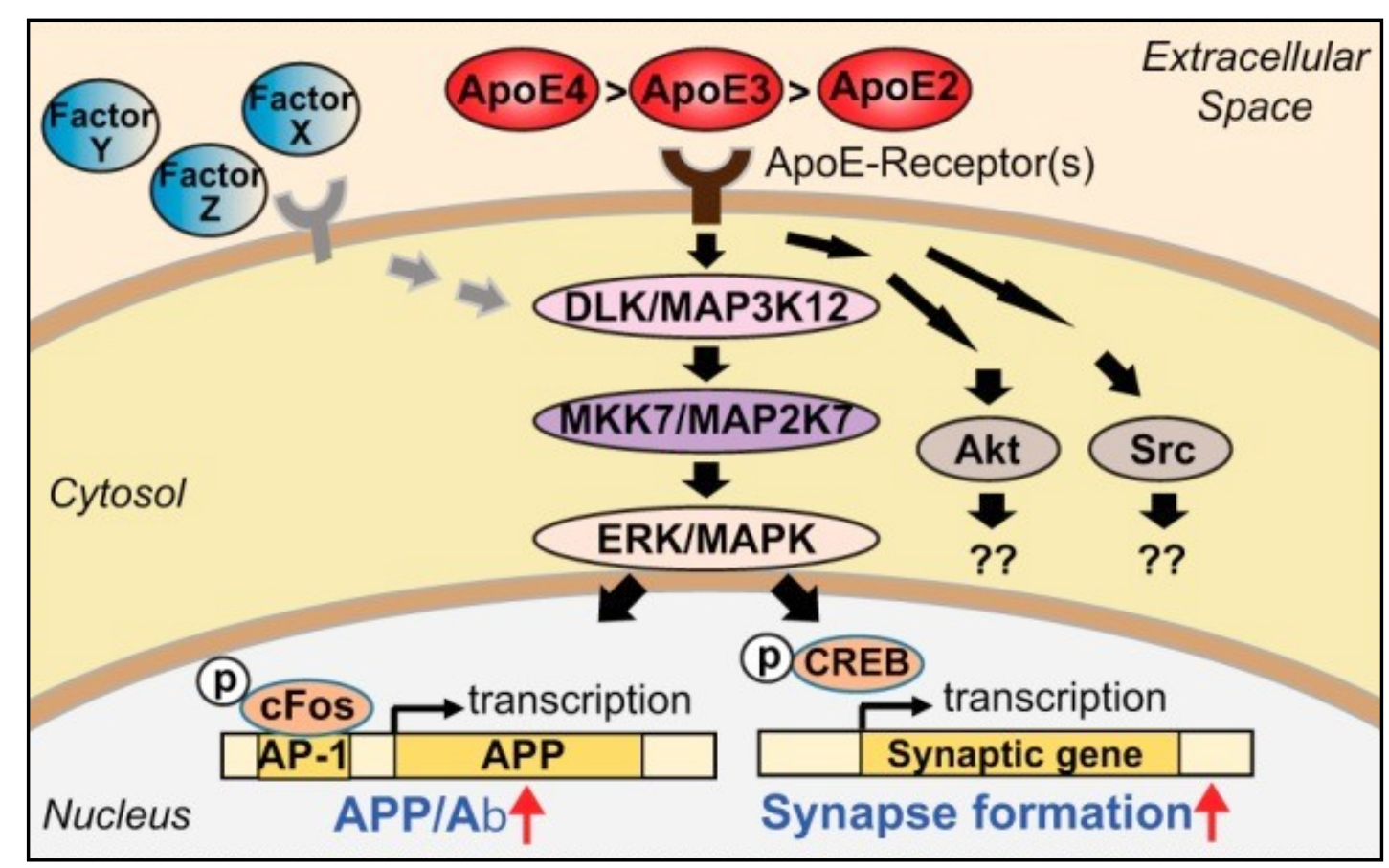

Fig. 2. ApoE effect on DLK/MKK7/ERK Cascade promoting APP function. ApoE activates the DLK/MKK7/ ERK cascade stimulating both cFos and CREB phosphorylation. This cascade results in amyloid precursor protein (APP) transcription and synaptogenesis. The stimulation of APP directly results in an increase of amyloid beta synthesis. ApoE4 has a greater effect on the stimulation of the cascade followed by ApoE3 and then ApoE2. Diagram Sourced from Huang, et al. [27]. 


\section{Cellular Physiology Cell Physiol Biochem 2021;55:773-783 \\ \begin{tabular}{ll|l} 
and Biochemistry $10.33594 / 000000475$ & C 2021 The Author(s). Published by \\
Published online: 15 December 2021 & Cell Physiol Biochem Press GmbH\&Co. KG
\end{tabular} \\ Jervies et al.: Apolipoprotein E4 in Alzheimer's Disease}

\section{Inhibition of ApoE4}

The ApoE protein has been found to play an important role in cholesterol and other lipid transport in the brain throughout the bloodstream. It has been stated that carriers of the ApoE4 variant are at far greater risk of AD than others without the gene, however, the reason behind this is still largely unclear [55].

The relationship between ApoE and $A \beta$ aggregation and metabolism is still mostly unknown however advancements in understanding are constantly occurring. It was identified that the ApoE isoforms could activate the DLK-MKK7-ERK1/2 cascade in 2017, in which it was found that ApoE4 had the highest activation of the cascade leading to overexpression of APP (Fig. 2). This pathway with increased levels of ApoE resulted in increased AP-1 transcription factor stimulation which led to higher APP transcription and $A \beta$ production levels in mouse models [27]. The overexpression of APP is troubling as this leads to increasing A $\beta$ levels and as a result forms more risk of developing $A \beta$ plaques. Therefore, reduced levels of ApoE4 will result in a decrease in APP transcription overexpression and return A $\beta$ nearer to ideal levels, which reduces the chance of forming toxic $A \beta$ plaques.

$A \beta 42$ clearance from plasma was also proved far less effective when ApoE4 was present compared to the other isoforms. The results proved that the APOE gene does affect the clearance rate of $A \beta$ especially the peripheral clearance of $A \beta 42$ [56]. This is possibly due to a variety of reasons however ApoE4 is less effective at transporting A 342 across the bloodbrain barrier and impairs the endocytic degradation of $A \beta$ and microglia proteases [57].

The ApoE4 effects on tau have been less researched however it has been identified that the binding of tau to the ApoE protein reduces the phosphorylation of tau. ApoE4 could not bind to tau as effectively as other isoforms of ApoE. This causes higher levels of tau phosphorylation eventually leading to hyperphosphorylation and neurofibrillary tangles. ApoE proteins are made up containing an $\mathrm{N}$-terminal and a C-terminal domain where the $\mathrm{N}$-terminal is the receptor-binding region and the C-terminal is the fat binding region [58]. Overexpression of the C-terminal ApoE region causes an increase in hyperphosphorylated tau, neuronal damage and loss, and memory degradation. ApoE4 gene carriers were found to express higher levels of ApoE C-terminal fragment production within AD patients [59].

Inhibition of ApoE4 ideally will provide a solution to combat these effects and therefore reduce the levels of $A \beta$ aggregation and plaque formation in addition to hyperphosphorylation of tau and reduce the level of neurofibrillary tangles. Currently, very few inhibitors have shown promise for use as future AD treatments, however, constant research is occurring in the field to produce results.

\section{Disclosure Statement}

The authors declare that no conflicts of interest exist.

\section{References}

1 Katsuno M, Sahashi K, Iguchi Y, Hashizume A: Preclinical progression of neurodegenerative diseases. Nagoya J Med Sci 2018;80:289-298.

2 Hou Y, Dan X, Babbar M, Wei Y, Hasselbalch SG, Croteau DL, Bohr VA: Ageing as a risk factor for neurodegenerative disease. Nat Rev Neurol 2019;15:565-581.

3 Weller J, Budson A: Current understanding of Alzheimer's disease diagnosis and treatment. F1000Res 2018;7:1161.

4 Australien Institute of Health and Welfare: Causes of death (leading causes of death 2018). Release Date 23 Jul 2020. URL: https://www.aihw.gov.au/reports/australias-health/causes-of-death.

5 Awada AA: Early and late-onset Alzheimer's disease: What are the differences?. J Neurosci Rural Pract $2015 ; 6: 455-456$. 
6 Bondi MW, Edmonds EC, Salmon DP: Alzheimer's Disease: Past, Present, and Future. J Int Neuropsychol Soc 2017;23:818-831.

7 Chi H, Chang HY, Sang TK: Neuronal Cell Death Mechanisms in Major Neurodegenerative Diseases. Int J Mol Sci 2018;19:3082.

8 Raji CA, Lopez OL, Kuller LH, Carmichael OT, Becker JT: Age, Alzheimer disease, and brain structure. Neurology 2009;73:1899-1905.

9 Congdon EE, Sigurdsson, EM: Tau-targeting therapies for Alzheimer disease. Nat Rev Neurol 2018;14:399415.

10 Buchman AS, Bennett DA: Loss of motor function in preclinical Alzheimer's disease. Expert Rev Neurother 2011;11:665-676.

11 Bu XL, Jiao SS, Lian Y, Wang YJ: Perspectives on the Tertiary Prevention Strategy for Alzheimer's Disease. Curr Alzheimer Res 2016;13:307-316.

12 Chen G, Xu T, Yan Y, Zhou Y, Jiang Y, Melcher K, Xu HE: Amyloid beta: structure, biology and structure-based therapeutic development. Acta Pharmacol Sin 2017;38:1205-1235.

13 Wang S, Mims PN, Roman RJ, Fan F: Is Beta-Amyloid Accumulation a Cause or Consequence of Alzheimer's Disease? J Alzheimers Parkinsonism Dement 2016:1:7.

14 Seeman P, Seeman N: Alzheimer's Disease: $\beta$-Amyloid Plaque Formation in Human Brain. Synapse 2011;65:1289-1297.

15 Takahashi R, Nagao T, Gouras G: Plaque Formation and the Intraneuronal Accumulation of $\beta$-Amyloid in Alzheimer's Disease. Pathol Int 2017;67:185-193.

16 Guo T, Noble W, Hanger DP: Roles of tau protein in health and disease. Acta Neuropathol 2017;133:665704.

17 Ittner A, Ittner LM: Dendritic Tau in Alzheimer's Disease. Neuron 2018;99:13-27.

18 Mietelska-Porowska A, Wasik U, Goras M, Filipek A, Niewiadomska G: Tau Protein Modifications and Interactions: Their Role in Function and Dysfunction. Int J Mol Sci 2014;15:4671-4713.

19 Biswas S, Kalil K: The Microtubule-Associated Protein Tau Mediates the Organization of Microtubules and Their Dynamic Exploration of Actin-Rich Lamellipodia and Filopodia of Cortical Growth Cones. J Neurosci 2018;38:291-307.

20 Alonso AD, Cohen LS, Corbo C, Morozova V, ElIdrissi A, Phillips G, Kleiman FE: Hyperphosphorylation of Tau Associates With Changes in Its Function Beyond Microtubule Stability. Front Cell Neurosci 2018;12:338.

21 Noble W, Hanger DP, Miller CCJ, Lovestone S: The Importance of Tau Phosphorylation for Neurodegenerative Diseases. Front Neurol 2013;4:83.

22 Wang Y, Mandelkow E: Tau in physiology and pathology. Nat Rev Neurosci 2016;17:22-35.

23 Luppi M, Hitrec T, Di Cristoforo A, Squarcio F, Stanzani A, Occhinegro A, Chiavetta P, Tupone D, Zamboni G, Amici R, Cerri M: Phosphorylation and Dephosphorylation of Tau Protein During Synthetic Torpor. Front Neuroanat 2019;13:57.

24 Wernette-Hammond ME, Lauer SJ, Corsini A, Walker D, Taylor JM, Rall SC: Glycosylation of human apolipoprotein E. The carbohydrate attachment site is threonine 194. J Biol Chem 1989;264:9094-9101.

25 Kim J, Jiang H, Park S, Eltorai AEM, Stewart FR, Yoon H, Basak JM, Finn MB, Holtzman DM: Haploinsufficiency of Human APOE Reduces Amyloid Deposition in a Mouse Model of Amyloid- $\beta$ Amyloidosis. J Neurosci 2011;31:18007-18012.

26 Zhao L, Wu L: ApoE2 and Alzheimer's disease: time to take a closer look. Neural Regen Res 2016;11:412.

27 Huang YWA, Zhou B, Wernig M, Südhof TC: ApoE2, ApoE3, and ApoE4 Differentially Stimulate APP Transcription and $A \beta$ Secretion. Cell 2017;168:427-441.

28 Fernandez CG, Hamby ME, McReynolds ML, Ray WJ: The Role of APOE4 in Disrupting the Homeostatic Functions of Astrocytes and Microglia in Aging and Alzheimer's Disease. Front Aging Neurosci 2019;11:14.

29 Huang YWA, Zhou B, Nabet AM, Wernig M, Südhof TC: Differential Signaling Mediated by ApoE2, ApoE3, and ApoE4 in Human Neurons Parallels Alzheimer's Disease Risk. J Neurosci 2019;39:7408-7427.

30 Hemonnot A-L, Hua J, Ulmann L, Hirbec H: Microglia in Alzheimer Disease: Well-Known Targets and New Opportunities. Front Aging Neurosci 2019;11:233.

31 Ries M, Sastre M: Mechanisms of A $\beta$ Clearance and Degradation by Glial Cells. Front Aging Neurosci 2016;8:160. 


\section{Cellular Physiology Cell Physiol Biochem 2021;55:773-783 \begin{tabular}{ll|l} 
and Biochemistry & $\begin{array}{l}\text { DOl: 10.33594/000000475 } \\
\text { Published online: 15 December } 2021\end{array}$ & $\begin{array}{l}\text { C 2021 The Author(s). Published by } \\
\text { Cell Physiol Biochem Press GmbH\&Co. KG }\end{array}$ \\
\cline { 2 - 3 } &
\end{tabular}

32 Area-Gomez E, Larrea D, Pera M, Agrawal RR, Guilfoyle DN, Pirhaji L, Shannon K, Arain HA, Ashok A, Chen Q, Dillman AA, Figueroa HY, Cookson MR, Gross SS, Fraenkel E, Duff KE, Nuriel T: APOE4 is Associated with Differential Regional Vulnerability to Bioenergetic Deficits in Aged APOE Mice. Sci Rep 2020;10:1-20.

33 Kang SS, Ahn EH, Liu X, Bryson M, Miller GW, Weinshenke, D, Ye K: ApoE4 inhibition of VMAT2 in the locus coeruleus exacerbates Tau pathology in Alzheimer's disease. Acta Neuropathol 2021;142:139-158.

34 Kang SS, Ahn EH, Ye K: Delta-secretase cleavage of Tau mediates its pathology and propagation in Alzheimer's disease. Exp Mol Med 2020;52:1275-1287.

35 Lemprière S: APOE4 provokes tau aggregation via inhibition of noradrenaline transport. Nat Rev Neurol 2021;17:328-328.

36 Kuo CL, Pilling LC, Atkins JL, Masoli JAH, Delgado J, Kuchel GA, Melzer D: APOE e4 genotype predicts severe COVID-19 in the UK Biobank community cohort. J Gerontol A Biol Sci Med Sci 2020;75:2231-2232.

37 Wang C, Zhang M, Garcia G, Tian E, Cui Q Chen X, Sun G, Wang J, Arumugaswami V, Shi Y: ApoE-IsoformDependent SARS-CoV-2 Neurotropism and Cellular Response. Cell Stem Cell 2021;28:331-342.

38 Xiong N, Schiller MR, Li J, Chen X, Lin Z: Severe COVID-19 in Alzheimer's disease: APOE4's fault again?. Alzheimers Res Ther 2021;13:111.

39 Hippius H, Neundörfer G: The discovery of Alzheimer's disease. Dialogues Clin Neurosci 2003;5:101-108.

40 Ryan NS, Rossor MN, Fox NC: Alzheimer's disease in the 100 years since Alzheimer's death. Brain 2015;138:3816-3821.

41 DeTure MA, Dickson DW: The neuropathological diagnosis of Alzheimer's disease. Mol Neurodegener 2019;14:32.

42 Zetterberg H, Burnham SC: Blood-based molecular biomarkers for Alzheimer's disease. Mol Brain 2019;12:26.

43 Park M, Moon WJ: Structural MR Imaging in the Diagnosis of Alzheimer's Disease and Other Neurodegenerative Dementia: Current Imaging Approach and Future Perspectives. Korean J Radiol 2016;17:827-845.

44 Suppiah S, Didier MA, Vinjamuri S: The Who, When, Why, and How of PET Amyloid Imaging in Management of Alzheimer's Disease-Review of Literature and Interesting Images. Diagnostics (Basel) 2019;9:65.

45 Khanahmadi M, Farhud DD, Malmir M: Genetic of Alzheimer's Disease: A Narrative Review Article. Iran J Public Health 2015;44:892-901.

46 Lanoiselée HM, Nicolas G, Wallon D, Rovelet-Lecrux A, Lacour M, Rousseau S, Richard AC, Pasquier F, RollinSillaire A, Martinaud O, Quillard-Muraine M, de la Sayette V, Boutoleau-Bretonniere C, Etcharry-Bouyx F, Chauviré V, Sarazin M, le Ber I, Epelbaum S, Jonveaux T, Rouaud O: APP, PSEN1, and PSEN2 mutations in early-onset Alzheimer disease: A genetic screening study of familial and sporadic cases. PLoS Med 2017;14:e1002270.

47 Delabio R, Rasmussen L, Mizumoto I, Viani GA, Chen E, Villares J, Costa IB, Turecki G, Linde SA, Smith MC, Payão SL: PSEN1 and PSEN2 gene expression in Alzheimer's disease brain: a new approach. J Alzheimers Dis 2014;42:757-760.

48 Yiannopoulou KG, Papageorgiou SG: Current and Future Treatments in Alzheimer Disease: An Update. J Cent Nerv Syst Dis 2020; DOI: 10.1177/1179573520907397.

49 Mendiola-Precoma J, Berumen LC, Padilla K, Garcia-Alcocer G: Therapies for Prevention and Treatment of Alzheimer's Disease. BioMed Res Int 2016; DOI: 10.1155/2016/2589276.

50 Picciotto MR, Higley MJ, Mineur YS: Acetylcholine as a Neuromodulator: Cholinergic Signaling Shapes Nervous System Function and Behavior. Neuron 2012;76:116-129.

51 Eldufani J, Blaise G: The role of acetylcholinesterase inhibitors such as neostigmine and rivastigmine on chronic pain and cognitive function in aging: A review of recent clinical applications. Alzheimers Dement 2019;5:175-183.

52 Liu J, Chang L, Song Y, Li H, Wu Y: The Role of NMDA Receptors in Alzheimer's Disease. Front Neurosci 2019;13:43.

53 Wang R, Reddy PH: Role of Glutamate and NMDA Receptors in Alzheimer's Disease. J Alzheimers Dis 2017;57:1041-1048.

54 Atri A: Current and Future Treatments in Alzheimer's Disease. Semin Neurol 2019;39:227-240. 


\section{Cellular Physiology Cell Physiol Biochem 2021;55:773-783}

\begin{tabular}{ll|l} 
and Biochemistry & DOl: 10.33594/000000475 & P 2021 The Author(s). Published by \\
Published online: 15 December 2021 & Cell Physiol Biochem Press GmbH\&Co. KG
\end{tabular}

Jervies et al.: Apolipoprotein E4 in Alzheimer's Disease

55 Nuriel T, Angulo SL, Khan U, Ashok A, Chen Q, Figueroa HY, Emrani S, Liu L, Herman M, Barrett G, Savage V, Buitrago L, Cepeda-Prado E, Fung C, Goldberg E, Gross SS, Hussaini SA, Moreno H, Small SA, Duff KE: Neuronal hyperactivity due to loss of inhibitory tone in APOE4 mice lacking Alzheimer's disease-like pathology. Nat Commun 2017;8:1464.

56 Sharman MJ, Morici M, Hone E, Berger T, Taddei K, Martins IJ, Lim WLF, Singh S, Wenk MR, Ghiso J, Buxbaum JD, Gandy S, Martins RN: APOE genotype results in differential effects on the peripheral clearance of amyloid-beta42 in APOE knock-in and knock-out mice. J Alzheimers Dis 2010;21:403-409.

57 Li Z: New APOE-related therapeutic options for Alzheimer's disease. AIP Conf Proc 2019; DOI: 10.1063/1.5085515.

58 Chou CY, Jen WP, Hsieh YH, Shiao MS, Chang GG: Structural and Functional Variations in Human Apolipoprotein E3 and E4. J Biol Chem 2006;281;13333-13344.

59 Wang M, Turko IV: Mass spectrometry quantification revealed accumulation of C-terminal fragment of apolipoprotein E in the Alzheimer's frontal cortex. PloS One 2013;8:e61498. 